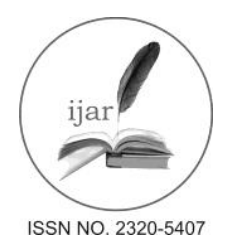

Journal homepage:http://www.journalijar.com
Journal DOI:10.21474/IJAR01

RESEARCH ARTICLE
INTERNATIONAL JOURNAL

OF ADVANCED RESEARCH

(1)

\title{
STRUCTURAL BEHAVIOUR OF WELDED STEEL BEAM-COLUMN CONNECTIONS UNDER CONCENTRATED LOAD.
}

Yassin Ali Ibrahim, Arsalan Hamad Hassan.

MSc in Civil Engineering Structures, Department of Building and Construction, Erbil Technology Institute Erbil Polytechnic University, Iraq

\section{Manuscript Info}

Manuscript History:

Received: 15 May 2016

Final Accepted: 19 June 2016

Published Online: July 2016

Key words:

Strand7, Deflection, Bending Stress,

Macaulay Method.

*Corresponding Author

Yassin Ali Ibrahim.

\begin{abstract}
This paper consists of an experimental work of a solid cantilever steel beam with a span of $1000 \mathrm{~mm}$ and a rectangular cross section of $75 \mathrm{~mm} \times 20 \mathrm{~mm}$; the beam is connected to asolid column by $6 \mathrm{~mm}$ arc welding, strain gauge and strain indicator were used to measure strains and dial gauge to measure deflections. The experimental results of the bending stresses and deflections are compared to with the results from theory of Macaulay Methods and computer program called Strand7.

The agreement is found quiet enough and satisfied for experimental and Strand7 results for both deflection and bending stress.

For the theoretical results, there is a good consensus for bending stress values with the experimental values. Due to deficiency of shear and torsional forces in Macaulay Method, there are a high percentages difference between Macaulay Method and both experimental Method and Strand7 deflection values.
\end{abstract}

Copy.Right, IJAR, 2013, All rights reserved.

\section{Introduction:-}

Welding is a process of connecting pieces of metal together by application of heat with or without pressure. For welding structural steel work, the most commonly used technique is the electric arc process in which the pieces of metal to be joined and fused together by an electric arc. Additional metal being added at the same time from a rod or wire (1).

Dimitrakis (2) used a special designed part termed a stress diffuser with beam-column connections in which the beam web and bottom flange are separated near the weld access hole, was found to eliminate the high stress concentration at the weld access hole and reduce the high degree of local bending inthe beam flange by $49 \%$ and the maximum principal stress at $2.54 \mathrm{~mm}$ from the column face was reduced by $31 \%$. The weld access hole is a structure technique that allows welding flange of $\mathrm{T}$ beam and $\mathrm{I}$ beam across their full width and also minimizing the induction of thermal stresses with a combination of partially releasing the welded section, avoiding welding the $\mathrm{T}$ section where the flange joints the web and improving cooling condition figure (1). The configuration adopted for web access holes also affects the performance of moment connections due to factors such as stress concentrations. 


\section{Weld Accessibility}

- Access holes are required for some welds, such as the welded flange connection shown to the right

- The top access hole allows for a continuous backing bar to be placed under the top flange

- The bottom access hole allows for complete access to weld the entire width of the bottom flange

- A detail of a weld access hole for a welded flange connection is shown below
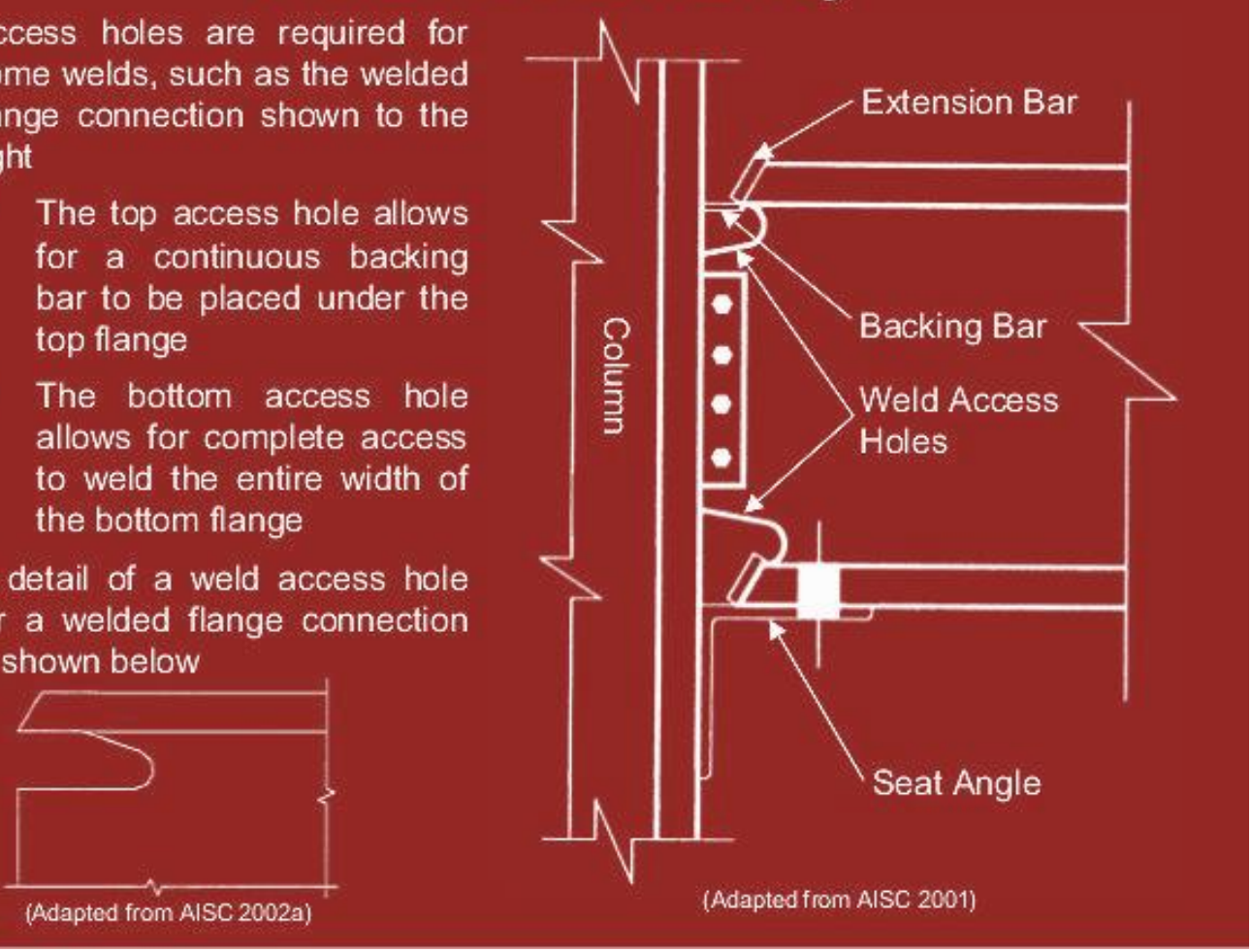

Figure 1:-Welding Access Hole.

Wai et.al. (3) Investigated the factors influencing the selection of elements in finite element analysis by considering the effects of different types of elements on the results of FEA. A simple case studied of I -beam subjected to an asymmetric loads is carried out by FEA. Three different models of the I-beam were prepared and analysed separately using $1 \mathrm{D}$ element, 2D element and 3D elements. The results of these models were compared with mathematical models of the I-beam. The FEA results of these models showed respectable agreement with the theoretical calculation despite the small and negligible errors in the analysis.

\section{Experimental Work:- \\ Preparation of Specimen:-}

The solid steel beam was connected to $2.5 \mathrm{~m}$ height column by using arc welding. A Strain gauge indicator attached by wires to the steel beamusing a gel pads to measure a strain. Four pads near the fixed end are connected to a beamandare shown in Figure (2). Switch balance indicator wasattached to strain gauge indicator Figure (3). A dial gauge used to read the beam deflection near the free end. The span of the specimen was $1000 \mathrm{~mm}$ and its section is $20 \mathrm{~mm}$ thickness with $75 \mathrm{~mm}$ height. The height of the column was $2500 \mathrm{~mm}$. $400 \mathrm{~mm}$ steel plate was welded with steel beam and bolted to column. The schematic diagram of the experimental work is shown in figure (4) 


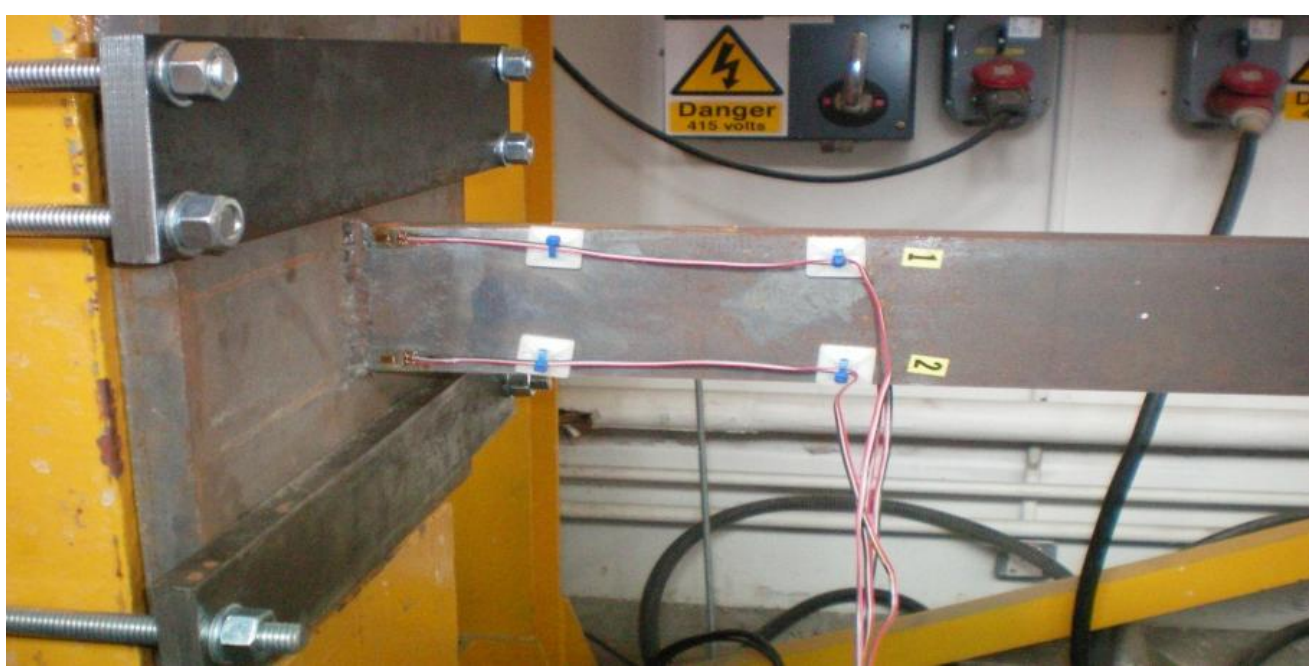

Figure 2:-Solid welded by solid and pads.

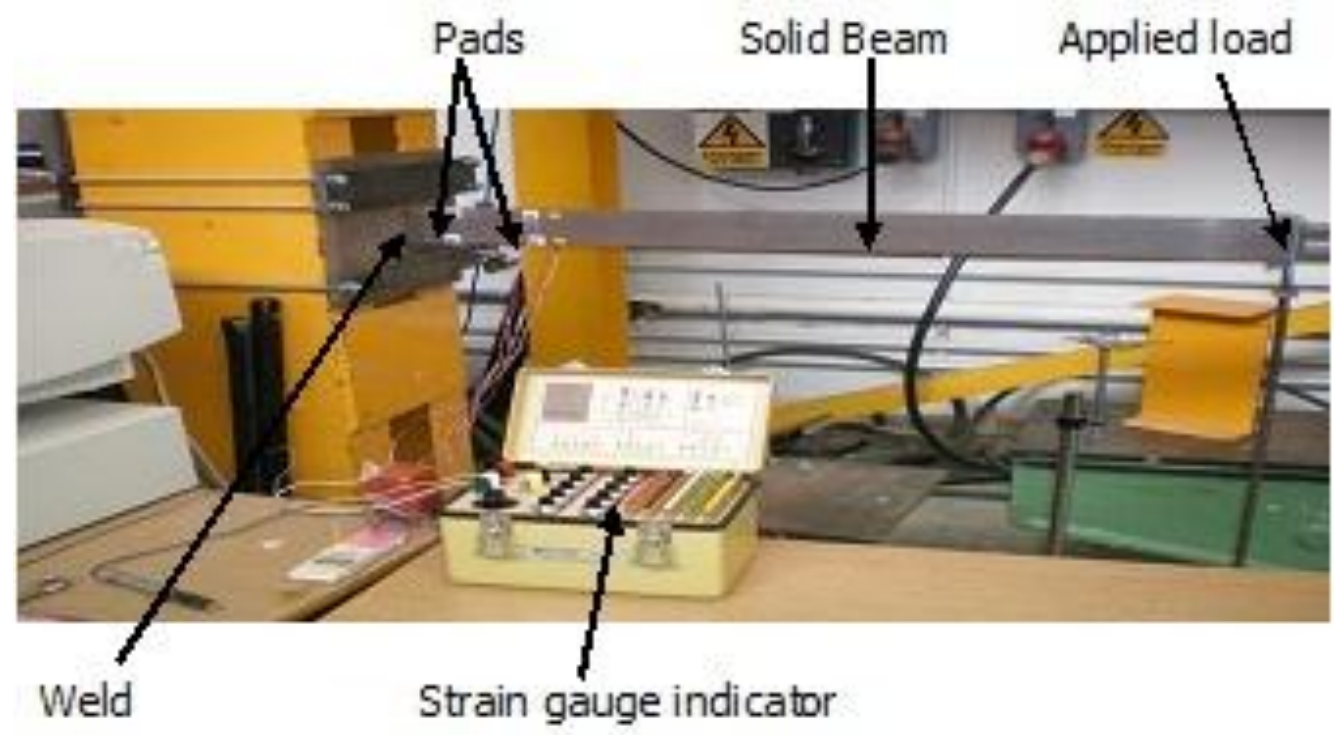

Figure 3:- Summary of experimental apparatus.

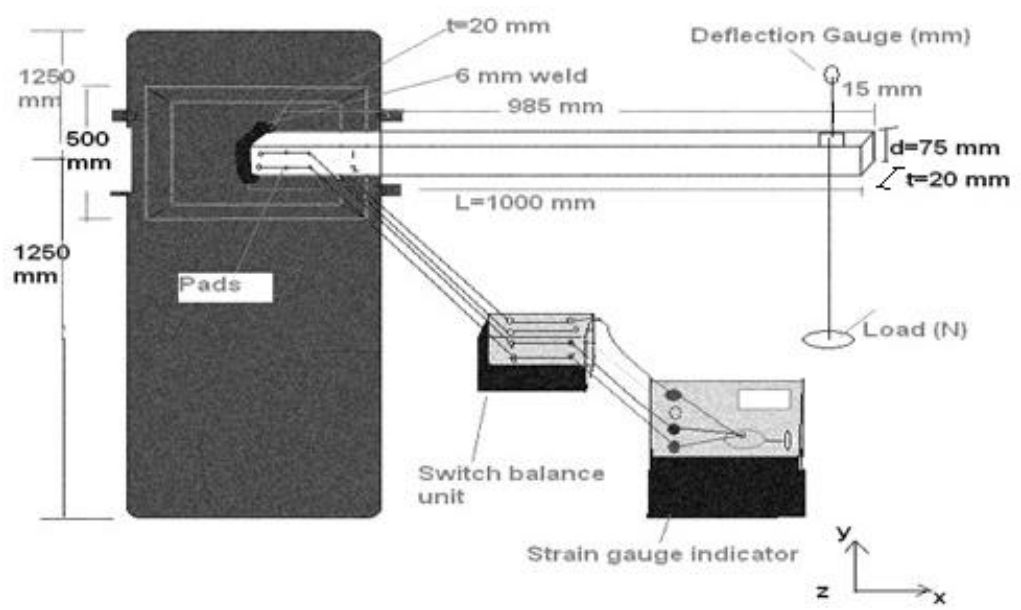

Figure 4:-Summary of work setup schematic diagram. 


\section{Testing Procedure:-}

The load was applied with increment, equal to 50 Newton up to 1000 newton. For each load increment, the readings for dial gauge deflections at thefree end and strain gauge at the fixed end of solid beam were taken. Theoverall results for deflection at the free end and bending stress at fixed endare shown in Table (1).

Table 1:-Experimental Results for Deflection and Bending Stress of Solid Beam.

\begin{tabular}{|c|c|c|}
\hline Load $(\mathrm{N})$ & Deflection $(\mathrm{mm})$ & Bending Stress $\left(\mathrm{N} / \mathrm{mm}^{2}\right)$ \\
\hline 0 & 0.00 & 0.00 \\
\hline 50 & 0.21 & 2.50 \\
\hline 100 & 0.41 & 4.80 \\
\hline 150 & 0.61 & 7.20 \\
\hline 200 & 0.81 & 9.00 \\
\hline 250 & 1.01 & 11.80 \\
\hline 300 & 1.22 & 14.10 \\
\hline 350 & 1.43 & 16.60 \\
\hline 400 & 1.64 & 19.00 \\
\hline 450 & 1.86 & 21.50 \\
\hline 500 & 2.06 & 23.80 \\
\hline 550 & 2.28 & 26.20 \\
\hline 600 & 2.48 & 28.20 \\
\hline 650 & 2.69 & 30.70 \\
\hline 700 & 2.89 & 32.90 \\
\hline 750 & 3.10 & 35.40 \\
\hline 800 & 3.31 & 37.70 \\
\hline 850 & 3.53 & 40.10 \\
\hline 900 & 3.75 & 42.80 \\
\hline 950 & 3.96 & 45.20 \\
\hline 1000 & 4.17 & 47.60 \\
\hline
\end{tabular}

\section{Strand7:-}

Strand7 is an easy and affordable Finite Element Analysis package designed to be used in small and largeConsulting and Engineering companies, involved in many different types of industries. As an additional feature Euro Technology has developed structural steel code compliance to SANS (4) 10162:1-2005 with the use of the Strand7 API.The Strand computer software was first developed by a group of academics from the University of Sydney and the University of New South Wales. Further to this early research work, an independent company called G+D Computing was established in 1988 to develop an FEA program that could be used commercially for industrial applications. In 1996 the company commenced work on a completely new software development specifically for the Windows platform. This product was first released in 2000 and was named Strand6. In 2005 the company also changed its name to Strand7 to better reflect its primary focus (5).

To check the deflection and bending stress of the tested cantilever solid steel beam within the elastic range, the finite element analysis was carried out using Strand7 program to testify the comparison with the experimental results.

The solid steel beam has been modelled as beam of $985 \mathrm{~mm}$ using Hexa20 solid element with 8 nodes in this paper Figure (5). The load attributes start from 50 Newtonup to 1000 Newtonapplied directly at the free end of the beam. The beam is fixed at one end and free at the other end and the beam was subdivided to 5 plates. Table (2) presents the dimension and material properties (6)of the beam used in the Strand7 analysis. The Strand7 results for deflection and bending stress are shown in Table (3) 


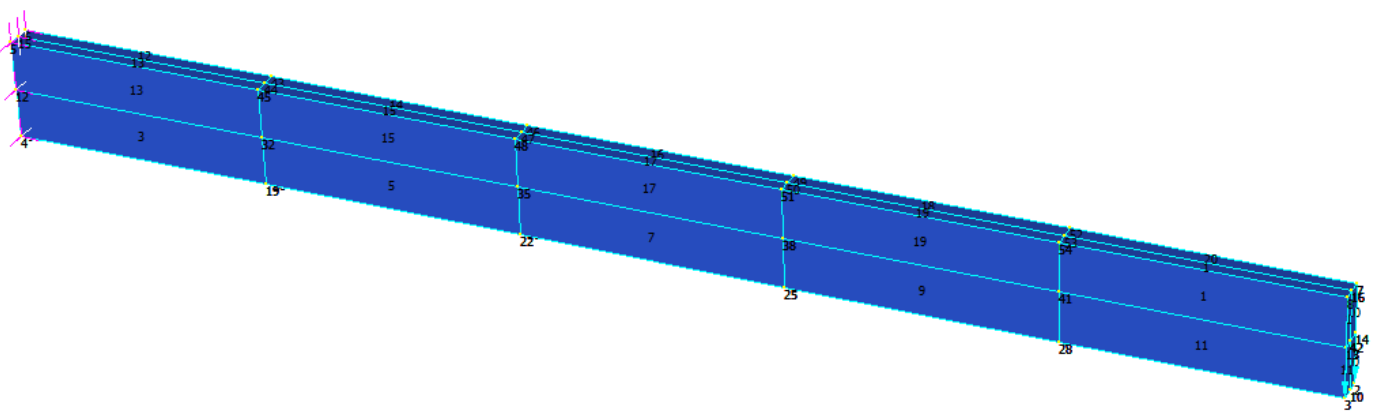

Figure 5:- Strand7 Model for Solid Beam3.

Table 2:-Solid Rectangular Beam Dimensions and Properties.

\begin{tabular}{|l|l|}
\hline Dimensions & 985 \\
\hline Length $(\mathrm{mm})$ & 75 \\
Height $(\mathrm{mm})$ & 20 \\
Width (mm) & \\
\hline Properties & 200000 \\
\hline Young's Modulus $\left(\mathrm{N} / \mathrm{mm}^{2}\right)$ & 0.30 \\
Poisson Ratio & \multicolumn{2}{|l|}{} \\
\hline
\end{tabular}

Table 3:-Strand7 Results for Deflection and Bending Stress for Solid Beam.

\begin{tabular}{|l|l|l|}
\hline Load $(\mathrm{N})$ & Deflection $(\mathrm{mm})$ & Bending Stress $\left(\mathrm{N} / \mathrm{mm}^{2}\right)$ \\
\hline 0 & 0.00 & 0.00 \\
\hline 50 & 0.22 & 2.40 \\
\hline 100 & 0.44 & 4.80 \\
\hline 150 & 0.66 & 7.20 \\
\hline 200 & 0.88 & 9.60 \\
\hline 250 & 1.10 & 11.98 \\
\hline 300 & 1.32 & 14.37 \\
\hline 350 & 1.54 & 16.77 \\
\hline 400 & 1.76 & 19.16 \\
\hline 450 & 1.98 & 21.56 \\
\hline 500 & 2.20 & 23.96 \\
\hline 550 & 2.42 & 26.30 \\
\hline 600 & 2.64 & 28.70 \\
\hline 650 & 2.86 & 31.14 \\
\hline 700 & 3.08 & 33.53 \\
\hline 750 & 3.30 & 35.90 \\
\hline 800 & 3.52 & 38.30 \\
\hline 850 & 3.74 & 40.72 \\
\hline 900 & 3.96 & 43.10 \\
\hline 950 & 4.18 & 45.50 \\
\hline 1000 & 4.40 & 47.90 \\
\hline
\end{tabular}

Theoretical Method (Macaulay's Method):-

Macaulay's Method is a means to find the equation that describes the deflected shape of a beam. From this equation, any deflection of interest can be found.

Before Macaulay's paper of 1919, the equation for the deflection of beams could not be found in closed form. Different equations for bending moment were used at different locations in the beam. 
Macaulay's Method enables us to write a single equation for bending moment for the full length of the beam. When coupled with the Euler-Bernoulli theory, it can then integrate the expression for bending moment to find the equation for deflection. Before looking at the deflection of beams, there are some preliminary results needed and these are introduced here.

When a structural member like beam, slab etc. are loaded due to dead load or super imposed load, they deflect in a particular pattern. The pattern is parabolic for applied uniformly distributed loading, triangular for point loading or concentrated loading, trapezoidal for two concentrated load acting at middle third of span or any convenient shape as per loading pattern. All the above patterns are for simple support.

But in this paper a cantilever beam is studied. The theoretical comparison is one of the procedures used to compare between bending stress and deflection in a beam with different type of methods. The cantilever beam is fixed at the supportwith $6 \mathrm{~mm}$ welding to a plate and loaded at the free end using a load increment from 50 Newton up to 1000 newton. The bending stress can be found at the fixed by using this equation $\left(\mathrm{M}_{\mathrm{x}} \mathrm{y} / \mathrm{I}_{\mathrm{xx}}\right)$. Macaulay Method is used to determine a deflection at the fixed end.The length of the beam is $985 \mathrm{~mm}$ and the height is $75 \mathrm{~mm}$ with $20 \mathrm{~mm}$ thickness.

$\mathrm{A}=\mathrm{b} \times \mathrm{d}=20 \times 75=1500 \mathrm{~mm}^{2}$

$y=\frac{d}{2}=\frac{75}{2}=37.5 \mathrm{~mm}$

$\mathrm{M}_{\mathrm{x}}=\mathrm{P} \times \mathrm{L}$

$\mathrm{I}_{\mathrm{xx}}=\frac{b d^{3}}{12}=\frac{20 \times 75^{3}}{12}=703125 \mathrm{~mm}^{4}$

$\mathrm{f}_{\mathrm{y}}=\frac{\mathrm{M}_{\mathrm{x}} \mathrm{y}}{\mathrm{I}_{\mathrm{xx}}}$

Where, $A$ is the Area of beam section, $y$ is the half depth of the beam, $M_{x}$ is the bending moment, $I_{z z}$ is the beam second moment of area, $\mathrm{f}_{\mathrm{y}}$ is the bending stress due to applied load $(\mathrm{P})$.

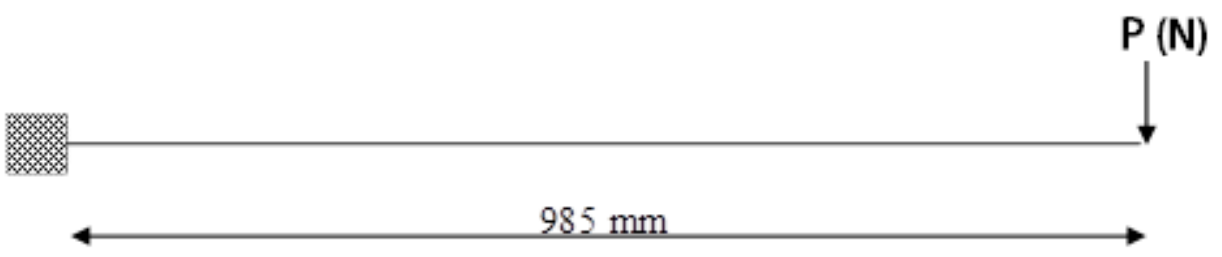

In this case, it is easier to consider the bending moment from the free end, as then reactions at the fixed end need not be determined.

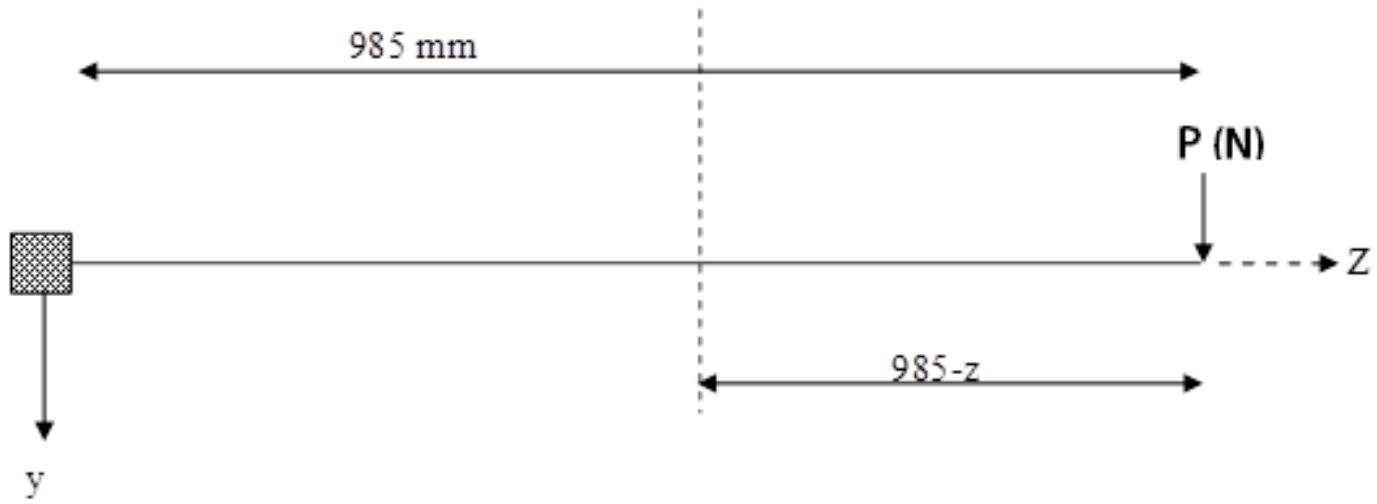


$\mathrm{M}=-\mathrm{P} \times(985-\mathrm{z}) \quad$ valid through the beam span, $0 \leq \mathrm{z} \leq 985$

$0 \leq \mathrm{z} \leq 985$ Substituting the moment expression into the moment - curvature equation:

$E I \frac{d^{2} y}{d z^{2}}=-M=P \times(985-z)$

(1)

Integration with respect to $\mathrm{z}$, gives the slope equation:

$E I \frac{d y}{d z}=-0.5 P \times(985-z)^{2}+A$

Integration with respect to $\mathrm{z}$, gives the deflection equation

$E I Y=(P / 3) \times(985-z)^{3}+A z+B$

By applying Boundary Condition $\mathrm{z}=0 \quad$ (at fixed end), the slope, $\frac{d y}{d z}=0$. The A value can be found and so on for $B$ value

By Substituting the constant $\mathrm{A}$ in the deflection equation, $\mathrm{z}=0$ (at the fixed end), the deflection, $\mathrm{y}=0$. The constant $\mathrm{B}$ value can be found.

$\mathrm{Y}=\frac{\mathrm{PL}^{3}}{3 \mathrm{EI}}$

Based on deflection formula and bending stress, the following sample calculation was obtained:

For a load of $250 \mathrm{~N}: \mathrm{Y}=\frac{\mathrm{PL}^{3}}{3 \mathrm{EI}}$

$$
\begin{gathered}
\mathrm{Y}=\frac{250 \times 985^{3}}{3 \times 2 \times 10^{5} \times 703125} \\
\mathrm{Y}=0.57 \mathrm{~mm} \\
\mathrm{f}_{\mathrm{y}}=\frac{\mathrm{M}_{\mathrm{x}} \mathrm{y}}{\mathrm{I}_{\mathrm{xx}}} \\
\mathrm{f}_{\mathrm{y}}=\frac{250 \times 985 \times 37.5}{703125} \\
\mathrm{f}_{\mathrm{y}}=13.13 \mathrm{~N} / \mathrm{mm}^{2}
\end{gathered}
$$


Values for corresponding load were calculated and tabulated as shown in Table (4) below.

Table 4:-Theoretical Results for Deflection and Bending Stress of Solid Beam

\begin{tabular}{|c|c|c|}
\hline Load $(\mathrm{N})$ & Deflection $(\mathrm{mm})$ & Bending Stress $\left(\mathrm{N} / \mathrm{mm}^{2}\right)$ \\
\hline 0 & 0.00 & 2.00 \\
\hline 50 & 0.11 & 5.25 \\
\hline 100 & 0.23 & 10.51 \\
\hline 150 & 0.34 & 13.13 \\
\hline 200 & 0.45 & 15.76 \\
\hline 250 & 0.57 & 18.39 \\
\hline 300 & 0.68 & 21.01 \\
\hline 350 & 0.79 & 23.64 \\
\hline 400 & 0.91 & 26.27 \\
\hline 450 & 1.02 & 28.89 \\
\hline 500 & 1.13 & 31.52 \\
\hline 550 & 1.25 & 34.15 \\
\hline 600 & 1.36 & 36.77 \\
\hline 650 & 1.47 & 39.40 \\
\hline 700 & 1.59 & 42.03 \\
\hline 750 & 1.70 & 44.65 \\
\hline 800 & 1.81 & 47.28 \\
\hline 850 & 1.93 & 49.91 \\
\hline 900 & 2.04 & 52.53 \\
\hline 950 & 2.15 & \\
\hline 1000 & 2.27 & \\
\hline
\end{tabular}

\section{Results and Discussion:-}

The parameters that had been investigated in this study are the deflection and bending stress for the cantilever beam by using load increment starting from $50 \mathrm{~N}$ up to $1000 \mathrm{~N}$. Figure (6) and (7) presents a Strand7 stress and Deflection distributions for a solid beam under a load of 1000 Newton.

The load's bending stress curve for entire loads for the welded beam-column connection are shown in Figure (8), there are a good consent between Strand7 and Experimental results. The average difference between them for bending stress are $1.04 \%$ and the average difference between the theoretical and experimental results for bending stress are $10.8 \%$.

For the load's deflection curvefor entire loads for the welded beam-column connection are shown in Figure (9). The deflection for the beam obtained from Strand7 model is close to experimental results and the average difference between them for deflection are $6.7 \%$ while the average difference between the theoretical and experimental results for deflection are $45 \%$ at the free end. The difference between the deflection value obtained from theoretical and experimental work for the beam-column connection are high and this is due to some reasons like torsion and shear leg. In theoretical calculation for deflection which is due to shear force and torsional force not included in deflection equation.

So this paper is concern only for elastic range for this beam and it's needed for future to study beam behaviour up to failure. 


\begin{tabular}{l} 
Brick Stess:Mean (MPa) \\
\hline $4.790569 \times 10^{2}$ [Bk:13,Nd:5] \\
$4.286294 \times 10^{2}$ \\
$3.277742 \times 10^{2}$ \\
$2.269191 \times 10^{2}$ \\
$1.260639 \times 10^{2}$ \\
$2.520877 \times 10^{1}$ \\
$-7.564638 \times 10^{1}$ \\
$-1.765015 \times 10^{2}$ \\
$-2.773567 \times 10^{2}$ \\
$-3.782118 \times 10^{2}$ \\
$-4.790670 \times 10^{2}[$ [Bk:2,Nd:1]
\end{tabular}

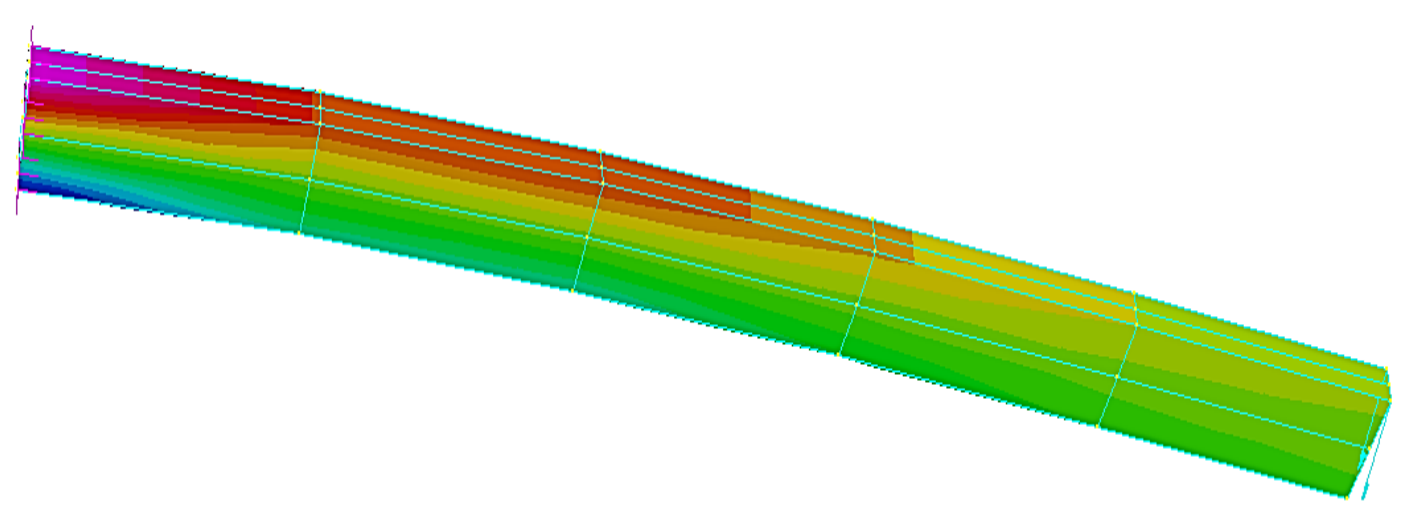

Figure 6:-Stress Distribution of Solid Beam due to Load of 1000 Newton.

$\frac{\text { Brid Disp:Dy (mm) }}{0.000000 \times 10^{0}}[$ [Bk:2,Nd:1]
$-2.313908 \times 10^{0}$
$-6.941723 \times 10^{0}$
$-1.156954 \times 10^{1}$
$-1.619735 \times 10^{1}$
$-2.082517 \times 10^{1}$
$-2.545298 \times 10^{1}$
$-3.008080 \times 10^{1}$
$-3.470861 \times 10^{1}$
$-3.933643 \times 10^{1}$
$-4.396424 \times 10^{1}[B k: 20, N d: 7]$

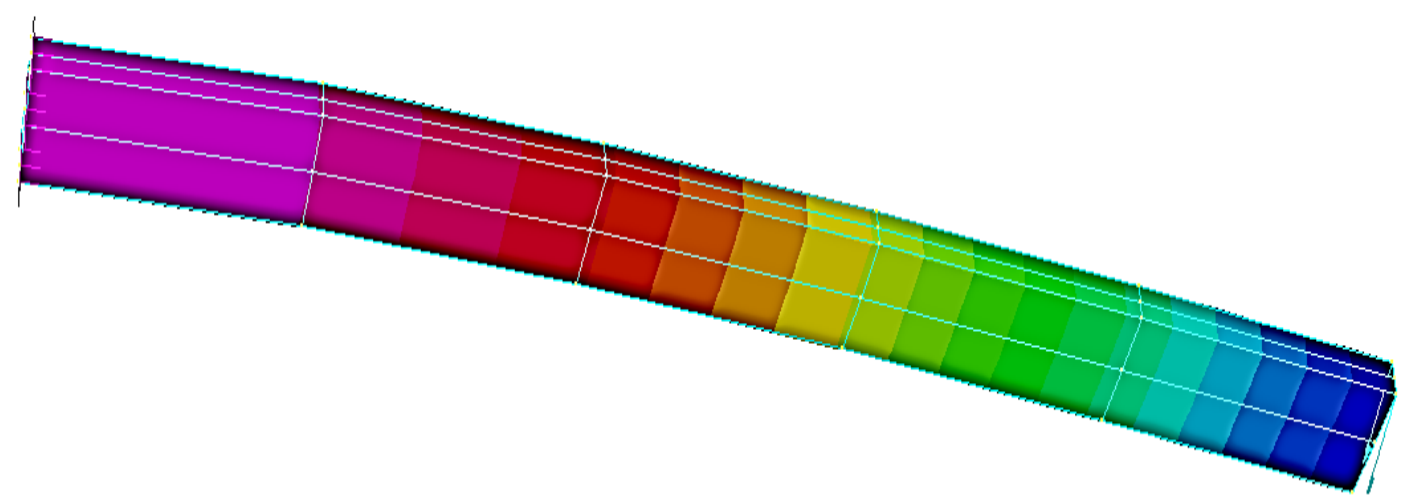

Figure 7:-Deflection of Solid Beam due to Load of 1000 Newton. 
Table 5:-Comparison between Experimental, Strand7, and Theoretical Results of Bending Stresses and Deflections for Welded Beam.

\begin{tabular}{|c|c|c|c|c|c|c|}
\hline & \multicolumn{2}{|c|}{ Experimental } & \multicolumn{2}{|c|}{ Strand7 } & \multicolumn{2}{|c|}{ Theory } \\
\hline $\begin{array}{l}\text { Load } \\
(\mathrm{N})\end{array}$ & $\begin{array}{l}\text { Deflection } \\
(\mathrm{mm})\end{array}$ & $\begin{array}{l}\text { Bending Stress } \\
\left(\mathrm{N} / \mathrm{mm}^{2}\right)\end{array}$ & Deflection (mm) & $\begin{array}{l}\text { Bending Stress } \\
\left(\mathrm{N} / \mathrm{mm}^{2}\right)\end{array}$ & $\begin{array}{l}\text { Deflection } \\
\quad(\mathrm{mm})\end{array}$ & $\begin{array}{c}\text { Bending Stress } \\
\left(\mathrm{N} / \mathrm{mm}^{2}\right)\end{array}$ \\
\hline 0 & 0.00 & 0.00 & 0.00 & 0.00 & 0.00 & 0.00 \\
\hline 50 & 0.21 & 2.50 & 0.22 & 2.40 & 0.11 & 2.63 \\
\hline 100 & 0.41 & 4.80 & 0.44 & 4.80 & 0.23 & 5.25 \\
\hline 150 & 0.61 & 7.20 & 0.66 & 7.20 & 0.34 & 7.88 \\
\hline 200 & 0.81 & 9.00 & 0.88 & 9.60 & 0.45 & 10.51 \\
\hline 250 & 1.01 & 11.80 & 1.10 & 11.98 & 0.57 & 13.13 \\
\hline 300 & 1.22 & 14.10 & 1.32 & 14.37 & 0.68 & 15.76 \\
\hline 350 & 1.43 & 16.60 & 1.54 & 16.77 & 0.79 & 18.39 \\
\hline 400 & 1.64 & 19.00 & 1.76 & 19.16 & 0.91 & 21.01 \\
\hline 450 & 1.86 & 21.50 & 1.98 & 21.56 & 1.02 & 23.64 \\
\hline 500 & 2.06 & 23.80 & 2.20 & 23.96 & 1.13 & 26.27 \\
\hline 550 & 2.28 & 26.20 & 2.42 & 26.30 & 1.25 & 28.89 \\
\hline 600 & 2.48 & 28.20 & 2.64 & 28.70 & 1.36 & 31.52 \\
\hline 650 & 2.69 & 30.70 & 2.86 & 31.14 & 1.47 & 34.15 \\
\hline 700 & 2.89 & 32.90 & 3.08 & 33.53 & 1.59 & 36.77 \\
\hline 750 & 3.10 & 35.40 & 3.30 & 35.90 & 1.70 & 39.40 \\
\hline 800 & 3.31 & 37.70 & 3.52 & 38.30 & 1.81 & 42.03 \\
\hline 850 & 3.53 & 40.10 & 3.74 & 40.72 & 1.93 & 44.65 \\
\hline 900 & 3.75 & 42.80 & 3.96 & 43.10 & 2.04 & 47.28 \\
\hline 950 & 3.96 & 45.20 & 4.18 & 45.50 & 2.15 & 49.91 \\
\hline 1000 & 4.17 & 47.60 & 4.40 & 47.90 & 2.27 & 52.53 \\
\hline
\end{tabular}

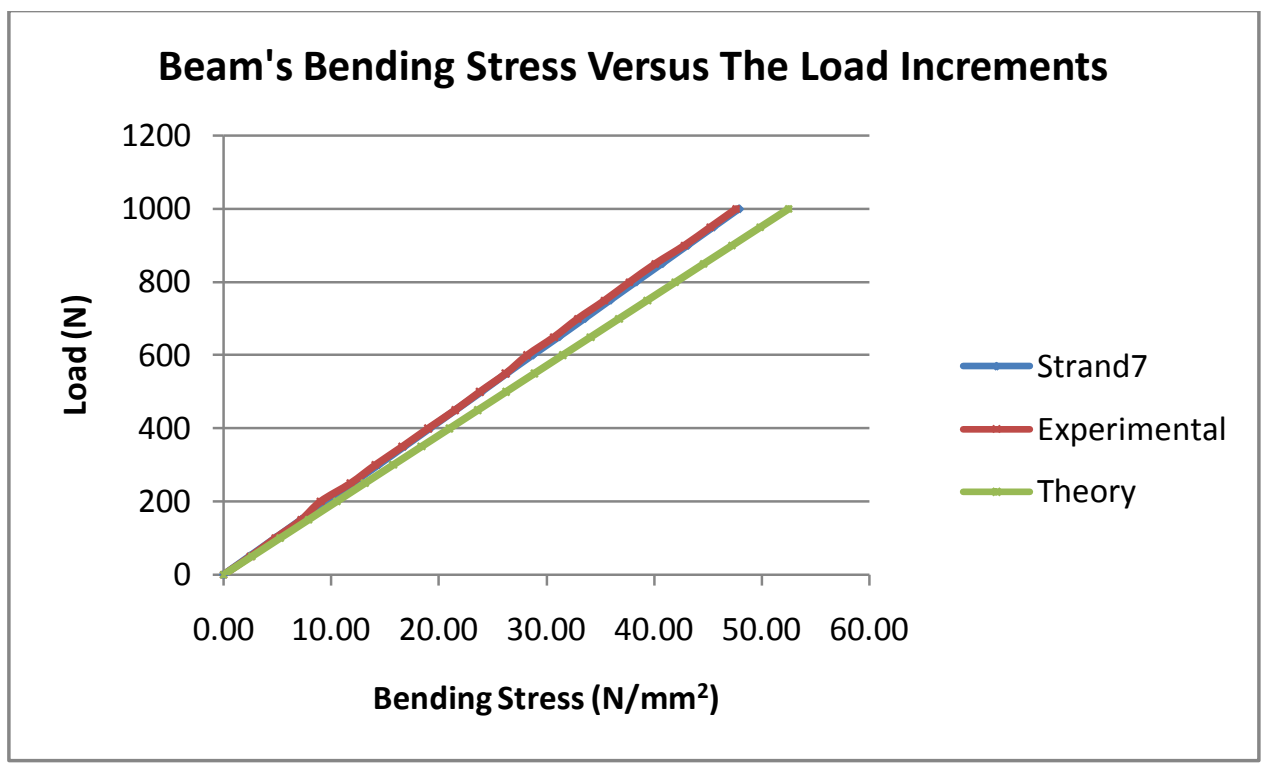

Figure 8:-Beam's Bending Stress Due to the Load Increments. 


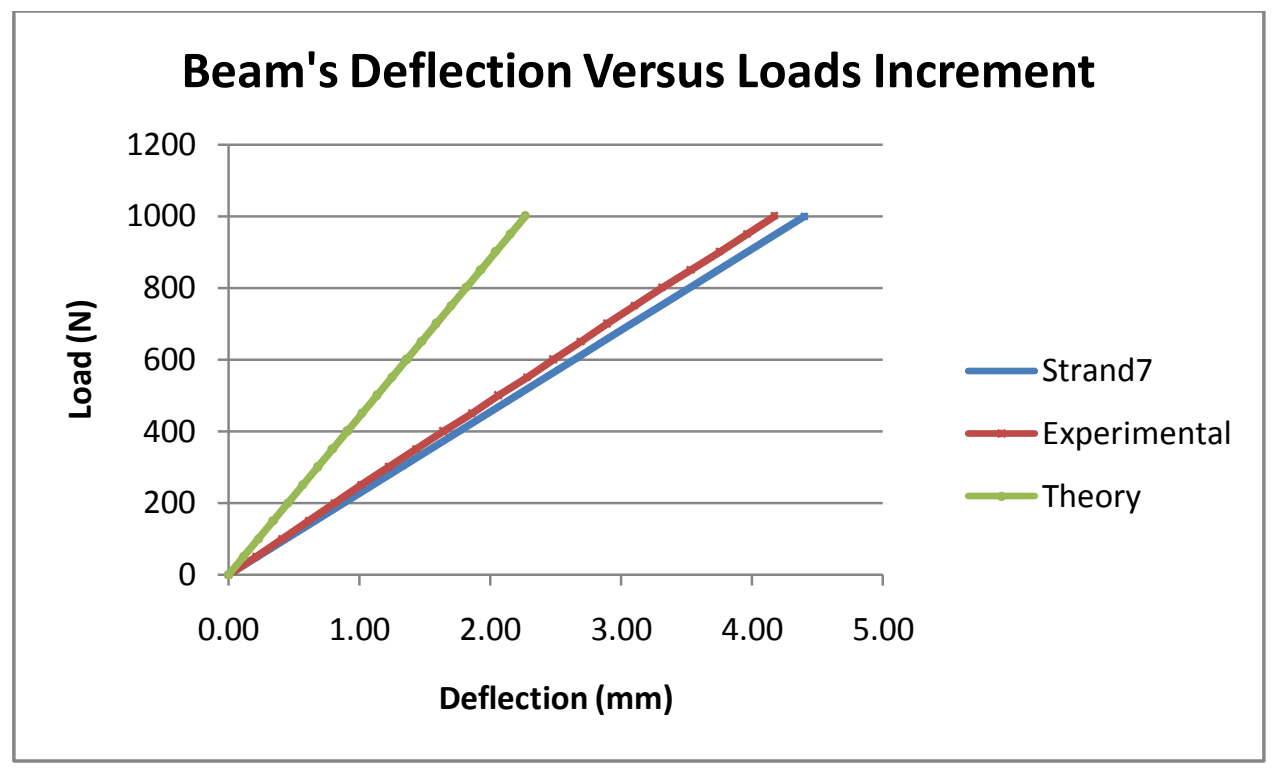

Figure 9:-Beam's Deflection due to Load Increments.

\section{Conclusion:-}

FEA of this joint offers the possibility to simulate their actual behaviour at low costs and in a relatively short execution time compared with the experimental tests. Strand7 program has provided results close to those obtained through experimental tests for deflection and bending stress.

For the theoretical results, there is a good agreement for bending stress values with the experimental values. Due to deficiency of shear and torsional forces in Macaulay Method, there are high percentages differences between Macaulay Method, and both experimental Method and Strand7 deflection values.

\section{Reference:-}

1. Fundamentals of Professional welding, (1985) Welding Terminology. New York: Sweet Haven.

2. Dimitrakis, S.D. and Lawrence, F.V. (2002) Journal of material in civil engineering. Application of Stress diffuser to Beam-Column Connections. Vol. 14, No. 1, pp. 84-89.

3. Wai Che Mun, Ahmed Rival, Omar Bapokutty, Effect of Elements on Linear Elastic Stress Analyses: A finite Elemen Approach, Volume 2, Issue 10. October 2013, IJRET P561-567

4. Strand7, Finite Element Analysis. (2015). Available at

5. http://www.strand7.com/html/specifications.htm

6. Composites, Cogit. Advanced French User Website. Available at

7. http://www.cogit-composites.com/page/index.php?c=17\&p=55 (Accessed 01 September 2015)

8. Draycott, T. and Bullman, P. (2009). Structutural Elements Design Manual Working With EuroCodes. 2nd ed. Oxford: Elsevier Ltd. 193-202. 